\title{
Kinetic fractionation of gases by deep air convection in polar firn
}

\author{
K. Kawamura ${ }^{1,2}$, J. P. Severinghaus ${ }^{3}$, M. R. Albert ${ }^{4,5}$, Z. R. Courville ${ }^{4,5}$, M. A. Fahnestock ${ }^{6}$, T. Scambos ${ }^{7}$, E. Shields ${ }^{3}$, \\ and C. A. Shuman 8 \\ ${ }^{1}$ National Institute for Polar Research, Tachikawa, Tokyo, Japan \\ ${ }^{2}$ Institute of Biogeosciences, Japan Agency for Marine-Earth Science and Technology, Natsushima-cho, Yokosuka, Japan \\ ${ }^{3}$ Scripps Institution of Oceanography, University of California, San Diego, CA, USA \\ ${ }^{4}$ Thayer School of Engineering, Dartmouth College, Hanover, NH, USA \\ ${ }^{5}$ Cryospheric and Terrestrial Sciences Division, Cold Regions Research and Engineering Laboratory, Hanover, NH, USA \\ ${ }^{6}$ Geophysical Institute, University of Alaska Fairbanks, Fairbanks, AK, USA \\ ${ }^{7}$ National Snow and Ice Data Center, Boulder, CO, USA \\ ${ }^{8}$ Cryospheric Sciences Branch, NASA Goddard Space Flight Center, Greenbelt, MD, USA
}

Correspondence to: K. Kawamura (kawamura@nipr.ac.jp)

Received: 31 January 2013 - Published in Atmos. Chem. Phys. Discuss.: 15 March 2013

Revised: 20 July 2013 - Accepted: 8 August 2013 - Published: 15 November 2013

\begin{abstract}
A previously unrecognized type of gas fractionation occurs in firn air columns subjected to intense convection. It is a form of kinetic fractionation that depends on the fact that different gases have different molecular diffusivities. Convective mixing continually disturbs diffusive equilibrium, and gases diffuse back toward diffusive equilibrium under the influence of gravity and thermal gradients. In nearsurface firn where convection and diffusion compete as gas transport mechanisms, slow-diffusing gases such as krypton $(\mathrm{Kr})$ and xenon $(\mathrm{Xe})$ are more heavily impacted by convection than fast diffusing gases such as nitrogen $\left(\mathrm{N}_{2}\right)$ and argon (Ar), and the signals are preserved in deep firn and ice. We show a simple theory that predicts this kinetic effect, and the theory is confirmed by observations using a newlydeveloped $\mathrm{Kr}$ and $\mathrm{Xe}$ stable isotope system in air samples from the Megadunes field site on the East Antarctic plateau. Numerical simulations confirm the effect's magnitude at this site. A main purpose of this work is to support the development of a proxy indicator of past convection in firn, for use in ice-core gas records. To this aim, we also show with the simulations that the magnitude of the kinetic effect is fairly insensitive to the exact profile of convective strength, if the overall thickness of the convective zone is kept constant. These results suggest that it may be feasible to test for the existence of an extremely deep ( $\sim 30-40 \mathrm{~m})$ convective zone, which has been hypothesized for glacial maxima, by future ice-core measurements.
\end{abstract}

\section{Introduction}

Trapped air in polar ice cores provides a unique archive of past atmospheric composition, and permits comparison of the past burden of greenhouse gases and associated climatic variations. Interpreting the gas records requires understanding the processes that modify the gas composition in the $\sim 100$-m-thick permeable firn layer on top of polar ice sheets, because the gas trapped in bubbles originates as air in the base of the firn (Schwander, 1989). These processes include gravitational fractionation of heavy isotopes and gases, due to settling of the heavier components under the influence of molecular diffusion in the stagnant portion of the firn (Schwander et al., 1989; Sowers et al., 1989). A second diffusive process is thermal fractionation, in which gases separate due to temperature gradients in the stagnant air column (Severinghaus et al., 1998; Lang et al., 1999; Landais et al., 2004; Grachev and Severinghaus, 2005). This portion of the firn is known as the "diffusive column" (Sowers et al., 1992).

Near the surface, the air is not stagnant and is convectively mixed, due primarily to flow driven by local pressure gradients arising from interaction of the wind with small topographic irregularities, a process known as "windpumping" (Colbeck, 1989; Clarke and Waddington, 1991). Buoyancydriven convection may also occur in winter, when dense cold air overlies the warmer firn (Powers et al., 1985; Severinghaus et al., 2001). Using measured firn permeability from the

Published by Copernicus Publications on behalf of the European Geosciences Union. 
Megadunes site, analysis of Albert et al. (2004) showed that natural convection is not only possible but is likely to occur there. This convective mixing reduces gravitational and thermal gas isotope fractionation, and tends to homogenize the gases with the free atmosphere. The layer in which isotope fractionation is inhibited is known as the "convective zone" (Sowers et al., 1992). In recent firn-air transport models, the convective zone is commonly formulated as eddy diffusion with different ways to parameterize the eddy diffusivity profiles (Kawamura et al., 2006; Buizert et al., 2012). The thickness of this convective zone varies from nearly zero to $23 \mathrm{~m}$ at those sites in modern firn that have been studied by withdrawing a depth profile of air samples from the firn and analyzing the gas composition (Schwander et al., 1993; Bender et al., 1994a; Battle et al., 1996; Severinghaus et al., 2001, 2010; Kawamura et al., 2006). Past variations in the thickness of the convective zone remain enigmatic and poorly understood, motivating the present study.

A search for a modern example of deep convection in firn was undertaken in an attempt to understand observations of lower-than-expected $\delta^{15} \mathrm{~N}$ values in ice core trapped air records for glacial periods from Antarctic sites such as Vostok (Sowers et al., 1992; Caillon et al., 2003; Bender et al., 2006) and Dome Fuji (Kawamura, 2000; Landais et al., 2006). Deep convection is one hypothesis to explain the low $\delta^{15} \mathrm{~N}$; the alternative hypothesis is that past firn thickness and hence gas age-ice age differences are overestimated, with implications for the relative timing of atmospheric $\mathrm{CO}_{2}$ increases and temperature increases at the ends of glacial periods (Bender et al., 2006; Parrenin et al., 2012, 2013). Regarding the latter, high impurity content of firn has recently been suggested to make the densification faster in glacial periods (Hörhold et al., 2012), but evidence is sparse and controversial (Capron et al., 2013).

An obvious candidate for deep convection is the Megadunes site on the East Antarctic plateau $\left(80.77914^{\circ} \mathrm{S}\right.$, $124.488^{\circ}$ E; Fahnestock et al., 2000; Severinghaus et al., 2010), located southeast of Vostok station, where near-zero snow accumulation rate occurs on the lee slopes of largescale snow antidunes in a strong katabatic wind regime (Courville et al., 2007). Low accumulation rate is expected to enhance permeability and thus air flow through firn, due to large grain size resulting from extended exposure to seasonal temperature fluctuations and extreme firn metamorphism (Albert et al., 2004; Severinghaus et al., 2010). Severinghaus et al. (2010) demonstrated conclusively that deep convection does indeed occur at the Megadunes field site, using a suite of 7 halocarbon and inert gas tracers.

Here we show that a previously unrecognized type of gas fractionation occurs in firn air columns subjected to intense convection. In contrast to gravitational and thermal fractionation, which are equilibrium processes, this third process arises from the disequilibrium caused by convective mixing. It is a form of kinetic fractionation that depends on the fact that different gases have different molecular diffusivi- ties. In essence, convective mixing continually disturbs diffusive equilibrium, and gases diffuse back toward equilibrium. Heavy gases and isotopes tend to diffuse more slowly than other gases, leading to their steady-state depletion in the firn interior relative to fast-diffusing gases. In a regime where convection and diffusion compete strongly as transport mechanisms, slow-diffusing gases are more heavily impacted by convection. In other words, the convective zone is thicker for slow-diffusing gases such as Xe than for fastdiffusing gases such as $\mathrm{N}_{2}$.

In the present work we show that a simple theory predicts this kinetic effect from first principles, and that the theory is confirmed by observations of heavy noble gas isotopes from the Megadunes site sampled in the 2004 field campaign reported by Severinghaus et al. (2010). We have developed a novel isotopic system for this purpose, highprecision ${ }^{86} \mathrm{Kr} /{ }^{82} \mathrm{Kr}$ and ${ }^{136} \mathrm{Xe} /{ }^{129} \mathrm{Xe}$ ratios. Numerical simulations confirm the effect's magnitude in the field with a more realistic mixing and gas transport parameterization than is possible from simple theory. The main reasons why this type of fractionation has been unrecognized despite being implicit in an existing firn gas transport model (Severinghaus et al., 2010) would be that (1) gas fractionation and convection have been considered mostly using nitrogen and argon (having similar molecular diffusivities), (2) that there have been no techniques to precisely measure $\mathrm{Kr}$ and Xe isotopes, and (3) that most firn columns have too small a convective zone to validate the theory.

The ultimate aim of this work is to support the development of a proxy indicator of past convection in firn, for use in ice-core gas records. This indicator exploits the kinetic effect on the isotopes of $\mathrm{Xe}$ and $\mathrm{Kr}$, which diffuse more slowly than $\mathrm{Ar}$ and $\mathrm{N}_{2}$.

\section{Simple theory of kinetic fractionation}

Kinetic fractionation by convection is predicted from first principles. Gas transport in a porous medium such as firn may be described by the 1-dimensional diffusion equation (e.g. Schwander et al., 1993) with an additional "eddy diffusion" term to represent the effect of convective mixing (Severinghaus et al., 2001, 2010; Kawamura et al., 2006; Buizert et al., 2012; Witrant et al., 2012):

$$
\begin{aligned}
& s \frac{\partial \delta}{\partial t}=\frac{\partial}{\partial z}\left[s D_{\mathrm{mol}}(z, T, p)\left(\frac{\partial \delta}{\partial z}-\frac{\partial \delta}{\partial z} \mathrm{eq}\right)+s D_{\text {eddy }}(z) \frac{\partial \delta}{\partial z}\right] \\
& -s w(z) \frac{\partial \delta}{\partial z}
\end{aligned}
$$

where $\delta$ is $\delta^{15} \mathrm{~N}$ (or $\delta$ for other gas pair), $t$ is time, $s$ is open porosity, $z$ is depth, $p$ is barometric pressure, $T$ is temperature $(\mathrm{K}), w$ is downward velocity of air due to bubble trapping, $D_{\text {mol }}$ is effective molecular diffusivity, and $D_{\text {eddy }}$ is eddy diffusivity to represent convective mixing. This equation treats molecular diffusion as arising from the difference 


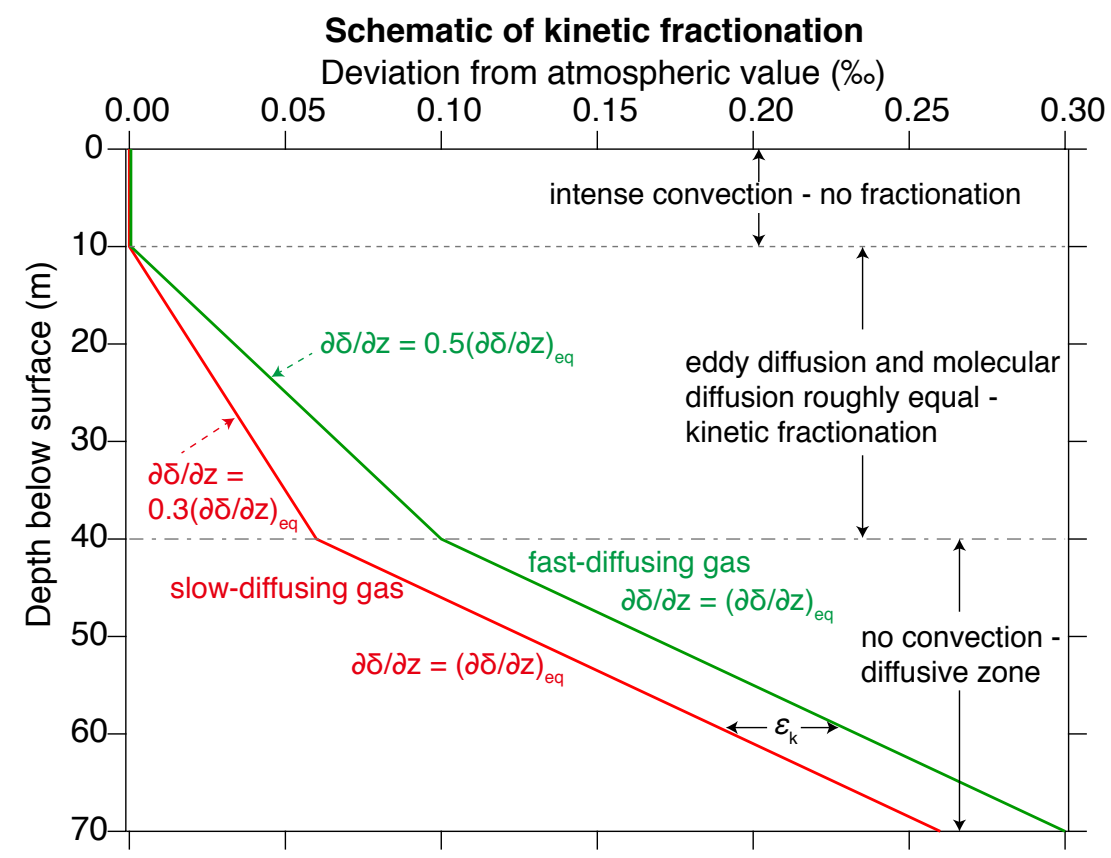

Fig. 1. Schematic illustrating the kinetic effect described here. Depth is plotted on the vertical axis, and the deviation of isotopic ratios $(\delta)$ from the atmospheric ratio is plotted on the horizontal axis. For clarity, the effects are exaggerated and an idealized convective zone is shown in which mixing is constant between 10 and $40 \mathrm{~m}$ and the Péclet number is 1 (for the fast-diffusing gas). Below $40 \mathrm{~m}$, there is no convection and the $\delta$ values exhibit the full gravitational equilibrium slope. Note that the amount of kinetic fractionation, $\varepsilon_{\mathrm{k}}$, does not increase in the diffusive zone.

between the actual gradient and the equilibrium gradient (Bender et al., 1994a; Severinghaus et al., 2001), where the equilibrium gradient contains terms for gravitational and thermal fractionation, and is given by:

$\frac{\partial \delta}{\partial z} \mathrm{eq} \cong \frac{\Delta m g q}{R T}-\Omega \frac{\partial T}{\partial z}$

where $\Delta m$ is mass difference $\left(0.001 \mathrm{~kg} \mathrm{~mol}^{-1}\right.$ for $\left.\delta^{15} \mathrm{~N}\right)$, $g$ is gravitational acceleration, $R$ is the gas constant, $q$ is $(\delta / 1000+1)$ and $\Omega$ is thermal diffusion sensitivity. At steady state, and neglecting thermal diffusion and the $q$ term $(\approx 1)$ for simplicity, the depth profile of $\delta$ becomes (Severinghaus et al., 2010):

$\delta(z) \cong \int_{0}^{z^{\prime}} \frac{1}{1+\frac{D_{\text {eddy }}}{D_{\text {mol }}}}\left[\frac{\Delta m g}{R T}\right] d z$

where eddy diffusivity is parameterized with a surface value $D_{0}$ and scale depth $H$ as $D_{\text {eddy }}=D_{0} \exp (-z / H)$. The ratio of diffusivities in this equation is closely related to the Péclet number:

$P e \equiv \frac{u L}{D_{\mathrm{mol}}}=\frac{D_{\text {eddy }}}{D_{\text {mol }}}$

It is a non-dimensional number that describes the ratio of convective transport to diffusive transport. Convective transport is typically given by a velocity of air $u$ times a length scale $L$. Eddy diffusivity may be thought of as a velocity times a characteristic length traveled before the fluid motion changes to a new (random) direction. An alternative way to conceptualize convective mixing, which does not require nonsteady air motions, is advective replacement of air in the firn with fresh air from the atmosphere. For example, air may enter the snow upstream of a small dune, flow under the dune, and exit downstream of the dune (e.g. Colbeck, 1989). Because of the strong horizontal layering in polar firn, with alternating high and low permeability layers, the actual flow path would be mostly horizontal, as suggested by numerical simulations (Albert, 1996) and demonstrated in field measurements (Albert and Shultz, 2002). In this case the Péclet number can be thought of as the ratio of the characteristic molecular diffusion time $z^{2} / D_{\text {mol }}$ to the advective replacement time $L / u$ of air flowing there from upstream within the layer. In this case $z$ would be the depth in the firn of the flowing air and $L$ would be the (mostly horizontal) path length of the bulk air motion involved in advective replacement. For the purposes of this paper it does not matter which process dominates, nonsteady random air motion or steady advective replacement, as they are mathematically equivalent, although they are physically different and would not be considered the same for more detailed analysis.

A key point is that eddy diffusivity is the same for all gases, because of the macroscopic nature of convective mixing, but molecular diffusivities vary among gases, typically 
decreasing with mass. Heavier gases with lower molecular diffusivities will therefore be affected more by convective mixing and will deviate more from the equilibrium profile (Fig. 1).

This difference in gas behavior is a form of kinetic fractionation, analogous to the familiar kinetic fractionation in irreversible gas fluxes, because it depends on differences in molecular diffusivities. In concept, a disequilibrium situation is set up by convective mixing, and gases diffuse back toward equilibrium, with heavier gases diffusing more slowly. This leads to a steady state depletion of heavy gases. This type of kinetic fractionation has much in common with diffusive fractionation in the firn in response to recent strong increases in atmospheric mixing ratios of $\mathrm{CO}_{2}$ and methane, which have created disequilibrium of the firn air with the overlying atmosphere (Trudinger et al., 1997). Both are essentially a response to disequilibrium.

The magnitude of the kinetic fractionation can be represented by the difference of fast- and slow-diffusing gas concentrations, normalized by the difference in relative mass $\Delta M$ (in a.m.u). For gas 1 with $\delta_{1}$ having molecular diffusivity $D_{\mathrm{mol}_{1}}$, and gas 2 with $\delta_{2}$ having molecular diffusivity $D_{\mathrm{mol}_{2}}$, the kinetic fractionation $\varepsilon_{\mathrm{k}}$ will be:

$\varepsilon_{\mathrm{k}}=\frac{\delta_{1}}{\Delta M_{1}}-\frac{\delta_{2}}{\Delta M_{2}}$

$=\int_{0}^{z} \frac{1}{1+P e_{1}(z)} \frac{\partial \delta_{1}}{\partial z}$ eqn $-\frac{1}{1+P e_{2}(z)} \frac{\partial \delta_{2}}{\partial z}$ eqn $\mathrm{d} z$

where the normalized gradient is given as:

$\frac{\partial \delta}{\partial z}$ eqn $=\frac{\partial \delta}{\partial z}$ eq $\frac{1}{\Delta M}$

In the limit $D_{\text {eddy }} \gg D_{\text {mol }}$, there is no fractionation at all, and in the limit $D_{\text {eddy }} \ll D_{\text {mol }}$, the equilibrium gradient holds for both gases so there is no kinetic fractionation. Only when $D_{\text {eddy }}$ and $D_{\text {mol }}$ are roughly of the same order of magnitude will there be kinetic fractionation. As in Eq. (3), some simplification is possible by noting that the equilibrium gradient depends on $\Delta m\left(\approx \Delta M \times 10^{-3} \mathrm{~kg} \mathrm{~mol}^{-1}\right)$, and by applying the approximation for gravitational fractionation $\left(\mathrm{q}_{1} \approx \mathrm{q}_{2} \approx 1\right)$, which is good to $10^{-3}$ for typical isotope pairs:

$\varepsilon_{\mathrm{k}} \cong \frac{g}{R T} \int_{0}^{z} \frac{1}{1+P e_{1}(z)}-\frac{1}{1+P e_{2}(z)} \mathrm{d} z$

It is helpful to express the Péclet numbers in terms of the ratio of the molecular diffusivities, as that is the key physical parameter that causes the effect:

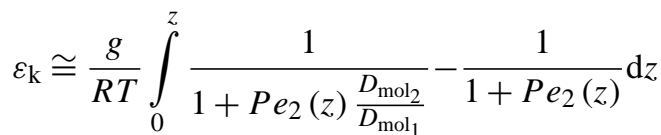

An important point is that this equation is valid only for trace
Table 1. Molecular diffusivity ratios used in this work.

\begin{tabular}{lc}
\hline Gas & Ratio \\
\hline${ }^{36} \mathrm{Ar}\left(D_{15} / D_{36}\right)$ & 1.0076 \\
${ }^{40} \mathrm{Ar}\left(D_{15} / D_{40}\right)$ & 1.0308 \\
${ }^{82} \mathrm{Kr}\left(D_{15} / D_{82}\right)$ & 1.3360 \\
${ }^{84} \mathrm{Kr}\left(D_{15} / D_{84}\right)$ & 1.3401 \\
${ }^{86} \mathrm{Kr}\left(D_{15} / D_{86}\right)$ & 1.3442 \\
${ }^{129} \mathrm{Xe}\left(D_{15} / D_{129}\right)$ & 1.5554 \\
${ }^{132} \mathrm{Xe}\left(D_{15} / D_{132}\right)$ & 1.5586 \\
${ }^{136} \mathrm{Xe}\left(D_{15} / D_{136}\right)$ & 1.5628 \\
\hline
\end{tabular}

Ratios are calculated from free-air binary diffusivities of the specified gas into air, from the method of Fuller et al., as reported in Reid et al. (1987).

gases diffusing into the major gas that is present. In other words, both molecular diffusivities given here are the binary diffusivities of trace gases with the major gas. In the case of air, which is our primary interest, the major gas is a fictitious species "air" with mass of $0.029 \mathrm{~kg} \mathrm{~mol}^{-1}$ (see Supplementary Information of Severinghaus et al., 2010). For practical reasons the natural choice for gas 2 is the gas pair ${ }^{15} \mathrm{~N}^{14} \mathrm{~N}$ ${ }^{28} \mathrm{~N}_{2}$, denoted $\delta^{15} \mathrm{~N}$, because it is easily measured and has a relatively large diffusivity compared to most trace gases in air. Thus, it is convenient to consider the Péclet number as that of ${ }^{15} \mathrm{~N}^{14} \mathrm{~N}^{28} \mathrm{~N}_{2}$, written $P e_{15}$ for brevity. The fractionation in this case is therefore the fractionation of a trace gas $y$ expressed as the gas pair $y-{ }^{29}$ air relative to the ${ }^{15} \mathrm{~N}^{14} \mathrm{~N}-{ }^{28} \mathrm{~N}_{2}$ pair:

$\varepsilon_{\mathrm{k}} \cong \frac{g}{R T} \int_{0}^{z^{\prime}} \frac{1}{1+P e_{15}(z) \frac{D_{15}}{D_{y}}}-\frac{1}{1+P e_{15}(z)} \mathrm{d} z$

For example, if gas $y$ is ${ }^{136} \mathrm{Xe}$, Eq. (9) applies to the fractionation of the pair ${ }^{136} \mathrm{Xe}^{29}$ air. If it is desired to compute the fractionation of a ratio of trace gases, for example the ${ }^{136} \mathrm{Xe}^{-}{ }^{129} \mathrm{Xe}$ ratio, Eq. (9) is not valid. The reason for this is essentially that molecular collisions between the two trace gases are rare, and instead the collisions are between a trace gas and air. Thus, the binary diffusivity of ${ }^{136} \mathrm{Xe}$ into ${ }^{129} \mathrm{Xe}$ is not physically relevant. Instead, the concentrations with air must be separately computed, and then combined afterwards:

$\varepsilon_{136-129}=\frac{\delta_{136-129}}{\Delta M_{136-129}}-\frac{\delta_{15}}{\Delta M_{15}}$
$\cong\left(\delta_{136-29}-\delta_{129-29}\right) \frac{1}{\Delta M_{136-129}}-\frac{\delta_{15}}{\Delta M_{15}}$

$\cong \frac{g}{R T} \int_{0}^{z^{\prime}}\left(\frac{\Delta m_{136-29}}{1+P e_{15}(z) \frac{D_{15}}{D_{136-29}}}-\frac{\Delta m_{129-29}}{1+P e_{15}(z) \frac{D_{15}}{D_{129-29}}}\right)$

$\frac{1}{\Delta M_{136-129}}-\frac{\Delta m_{15}}{1+P e_{15}(z)} \mathrm{d} z$ 


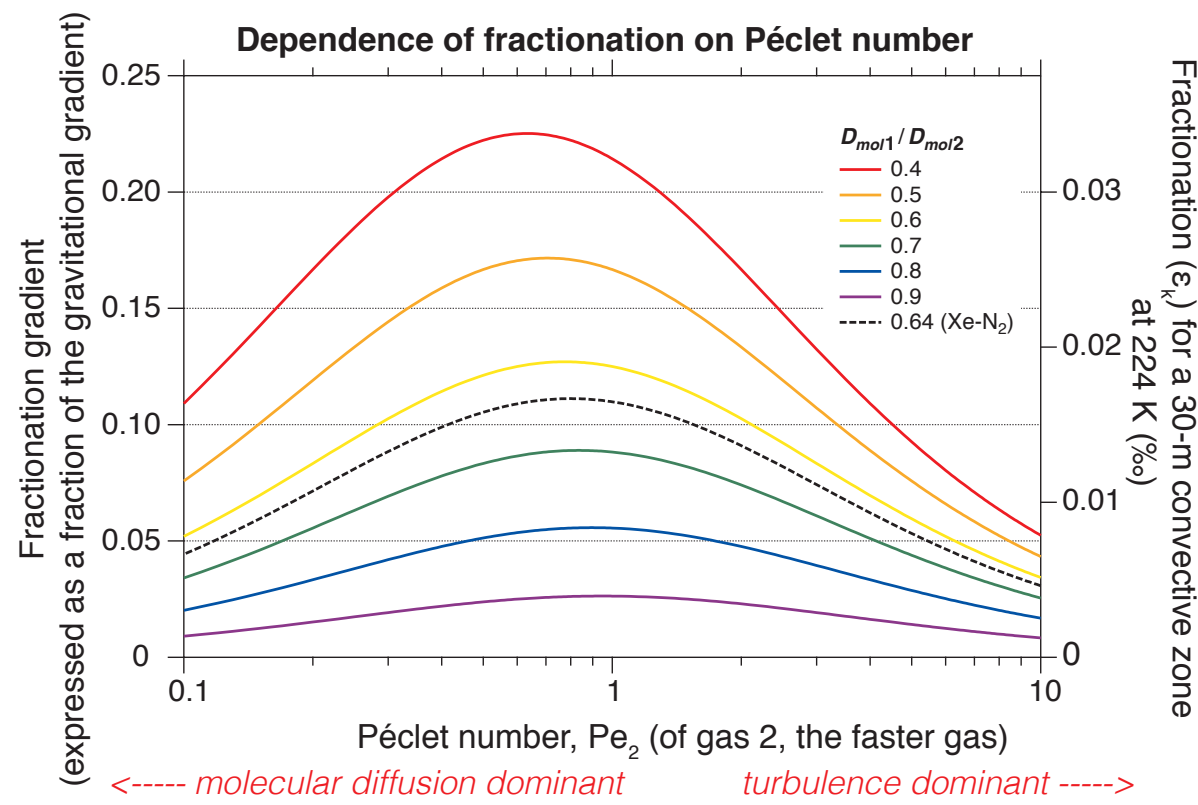

Fig. 2. Prediction of simple theory for dependence of fractionation on the Péclet number. The horizontal axis is the smaller of the two Péclet numbers, or that of the faster-diffusing gas. Different molecular diffusivity ratios are shown in different colors, as indicated by legend. For example, a diffusivity ratio of 0.64 would have a maximum fractionation equivalent to about $11 \%$ of the equilibrium gradient. The values for ${ }^{136} \mathrm{Xe}-{ }^{28} \mathrm{~N}_{2}$ are shown in the dashed black line. These calculations presuppose that $P e$ is constant with depth within the convective zone.

In practice, we use the diffusivity of ${ }^{29} \mathrm{~N}_{2}$ into air as the diffusivity $D_{15}$ and for calculating $P e_{15}$ to better approximate the real collisions that ${ }^{29} \mathrm{~N}_{2}$ experiences (because some of the collisions are with $\mathrm{O}_{2}$, even though most collisions are with ${ }^{28} \mathrm{~N}_{2}$ ).

For example, if $P e_{15}$ is 1 (for simplicity), $z$ is $30 \mathrm{~m}$, the temperature is $224 \mathrm{~K}$, and the molecular diffusivities are as in Table 1, Eq. (10) becomes:

$\varepsilon_{136-129} \cong \frac{g z}{R T}\left[\left(\frac{107}{1+\frac{D_{15}}{D_{136-29}}}-\frac{100}{1+\frac{D_{15}}{D_{129-29}}}\right) \frac{1}{7}-\frac{1}{2}\right]=-0.020 \%$

In other words, the ${ }^{136} \mathrm{Xe}^{-129} \mathrm{Xe}$ ratio (when normalized by dividing $\delta$ by the mass difference of 7) will be $0.02 \%$ less than expected from the observed $\delta^{15} \mathrm{~N}$. This corresponds to a $4 \mathrm{~m}$ deeper convective zone for Xe isotopes than for nitrogen isotopes. Although this is small, it is a measurable signal in practice as will be shown below.

Many approximations are made above including Eq. (2), the assumption of arithmetic additivity of $\varepsilon$ in Eq. (5), and the neglect of the $q$ term in Eq. (7). An exact treatment is useful for checking the validity of these approximations, and is given in Appendix A. The approximations given here appear to be valid at the level of $\leq 0.002 \%$ ofor typical polar conditions (see Sect. 5.1).

It is interesting to consider the behavior of the fractionation under widely varying Péclet number, as is likely to occur in Nature. It can be shown algebraically that the maximum fractionation occurs when the eddy diffusivity is equal to the geometric mean of the two molecular diffusivities, or when the product of the two Péclet numbers is 1 . The fractionation falls off by factors of 2 to 4 at Péclet numbers of 0.1 to 10 , respectively (Fig. 2). For comparison, Kawamura et al. (2006) found near-surface eddy diffusivities and Péclet numbers at four polar firn sites that were roughly in this range. These results suggest that at least some fractionation will occur in most naturally occurring convection regimes, even if the optimum conditions $\left(P e_{1} \times P e_{2}=1\right)$ are not exactly met.

\section{Experimental procedure}

Air samples were withdrawn from the Megadunes firn in January 2004 as part of a multi-investigator, multidisciplinary field campaign to better understand the genesis of megadunes and their possible implications for ice core paleorecords. Detailed air sampling procedures were explained elsewhere (Severinghaus et al., 2010), thus only a brief description is given here. Air was sampled from a borehole made with a $3^{\prime \prime}$ Eclipse ice core drill, using an inflatable rubber packer to seal the borehole. Firn air was withdrawn from the bottom of the borehole through a $1 / 4^{\prime \prime}$ Synflex ${ }^{\circledR}$ tubing that penetrates the packer, and filled by flushing in two-liter glass flasks for the inert gas measurements. In addition, a number of other air samples were taken for halocarbons, $\mathrm{CO}_{2}$ and methane concentrations and their isotopes (Severinghaus et al., 2010).

Flasks were analyzed at Princeton University for $\delta^{15} \mathrm{~N}$, $\delta^{18} \mathrm{O}$ of $\mathrm{O}_{2}, \delta \mathrm{O}_{2} / \mathrm{N}_{2}$, and $\delta \mathrm{Ar} / \mathrm{N}_{2}$, following standard procedures (Bender et al., 1994b, 2005), with extra integration to increase precision (Table 2). Flasks were shipped to SIO, 
Table 2. Typical measurement parameters for isotopes.

\begin{tabular}{lcccccccc}
\hline Gas & $\begin{array}{c}\text { Sample size } \\
(\mathrm{mL} \text { STP air })\end{array}$ & $\begin{array}{c}\text { Resistors } \\
\left(10^{9} \Omega\right)\end{array}$ & $\begin{array}{c}\text { Ion beam } \\
\text { intensity }(\mathrm{V})\end{array}$ & $\begin{array}{c}\text { Integration } \\
\text { time }(\mathrm{s})\end{array}$ & $\begin{array}{c}\text { Changeover } \\
\text { cycles }\end{array}$ & $\begin{array}{c}1 \sigma \text { error } \\
(\%)\end{array}$ & $\begin{array}{c}\Delta m \\
\left(10^{-3} \mathrm{~kg} \mathrm{~mol}\right)\end{array}$ & $\begin{array}{c}1 \sigma \text { error/ } \\
\Delta m\end{array}$ \\
\hline${ }^{29} \mathrm{~N}_{2} /{ }^{28} \mathrm{~N}_{2}$ & 2 & $0.3 / 300$ & 4 & 16 & 128 & 0.003 & 1 \\
${ }^{40} \mathrm{Ar} /{ }^{36} \mathrm{Ar}$ & 80 & $0.3 / 100$ & 7 & 16 & 80 & 0.008 & 4 & 0.003 \\
${ }^{86} \mathrm{Kr} / 82 \mathrm{Kr}$ & 80 & $1000 / 1000$ & 0.8 & 16 & $72-144$ & 0.016 & 4 & 0.002 \\
${ }^{136} \mathrm{Xe} /{ }^{129} \mathrm{Xe}$ & 350 & $1000 / 1000$ & 1 & 16 & $72-144$ & 0.030 & 7 & 0.004 \\
\hline
\end{tabular}

and then analyzed for ${ }^{40} \mathrm{Ar} /{ }^{36} \mathrm{Ar},{ }^{84} \mathrm{Kr} /{ }^{36} \mathrm{Ar},{ }^{132} \mathrm{Xe} /{ }^{36} \mathrm{Ar}$, and ${ }^{22} \mathrm{Ne} /{ }^{36} \mathrm{Ar}$ following the procedures of Severinghaus and Battle (2006) with increased sample size to $80 \mathrm{ml}$ STP, gettering time to $20 \mathrm{~min}$, and homogenization time to more than $2 \mathrm{~h}$. Duplicate or triplicate measurements were made for each flask. Pooled standard deviations of flask replicates from the mean for that sampling depth were $\pm 0.002 \%$ for $\delta^{15} \mathrm{~N}$ and $\pm 0.006 \%$ or $\delta^{40} \mathrm{Ar}$. The $\delta^{15} \mathrm{~N}$ and $\delta^{40} \mathrm{Ar}$ data were published by Severinghaus et al. (2010).

A subset of the flasks ( $n=23$ out of 42 total) was then analyzed for isotopic ratios of $\mathrm{Kr}$ and $\mathrm{Xe},{ }^{86} \mathrm{Kr} /{ }^{82} \mathrm{Kr}$ and ${ }^{136} \mathrm{Xe} /{ }^{129} \mathrm{Xe}$, using the same general procedures of Severinghaus and Battle (2006) with modifications. Noble gases were extracted from $\sim 350 \mathrm{ml}$ STP air samples as follows (the sample size was reduced to $\sim 80 \mathrm{ml} \mathrm{STP}$ if only $\mathrm{Kr}$ isotopes were measured). An aliquot of the flask air was taken by expansion into an evacuated 178-ml glass volume, and reactive gases in the aliquot were destroyed by an established gettering procedure (Severinghaus and Battle, 2006). Dual getter ovens were employed to accommodate enough getter sheets (56 strips of $8 \times 5.5 \mathrm{~mm}$ SAES ST-101 getter sheets) for the large sample size. Typical gettering time was $60 \mathrm{~min}$ at $900{ }^{\circ} \mathrm{C}$, with prior activation for $10 \mathrm{~min}$, followed by $\mathrm{H}_{2}$ absorption at $300^{\circ} \mathrm{C}$ for $5 \mathrm{~min}$. The noble gases were then cryogenically collected in a stainless steel dip tube immersed in liquid He. The valve on the dip tube was then closed and the above procedures were repeated once more. The noble gases from the second aliquot were collected in the same sample tube. After leaving the sample tube for more than $2 \mathrm{~h}$ at room temperature, the sample gas $(\sim 3.5 \mathrm{ml}$ STP noble gases) was then admitted into a mass spectrometer (Finnigan MAT 252), and dual-collector measurements were made for ${ }^{86} \mathrm{Kr} /{ }^{82} \mathrm{Kr}$ and ${ }^{136} \mathrm{Xe} /{ }^{129} \mathrm{Xe}$. Typical parameters for the measurements are detailed in Table 2. The ratios were measured against our reference gas, which is an artificial mixture of pure $\mathrm{Ar}, \mathrm{Kr}, \mathrm{Xe}$ and Ne with ratios similar to the atmosphere (Severinghaus and Battle, 2006). Corrections were made for all data to account for small biases due to pressure imbalance between sample and reference gases and due to the variation in $\mathrm{Kr} / \mathrm{Ar}$ and $\mathrm{Xe} / \mathrm{Ar}$ ratios (the so-called "pressure imbalance correction" and "chemical slope correction", respectively, and they are typically $\sim 0.01-0.02 \%$; Severinghaus et al., 2003).
Atmospheric samples collected in three flasks at the pier of SIO were measured with the same procedures $(n=7)$ before the sample measurements, and their mean value was used for standardizing the firn air data. The same samples were measured $(n=3)$ after the period of the firn air measurements (15 days) to confirm insignificant drift of the reference gas during the period. Pooled standard deviations of flask replicates from the mean for that sampling depth were $\pm 0.016 \%$ o for ${ }^{86} \mathrm{Kr} /{ }^{82} \mathrm{Kr}$ and $\pm 0.028 \%$ o for ${ }^{136} \mathrm{Xe} /{ }^{129} \mathrm{Xe}$ (one standard deviation), which are regarded as overall uncertainties of our measurements including those arising from sampling, storage and analysis. The average value of three Megadunes surface samples (i.e. atmosphere) agreed with the SIO atmospheric value within uncertainty $\left(-0.014 \%\right.$ for $\delta^{86} \mathrm{Kr}$ and $-0.010 \%$ ofor $\delta^{136} \mathrm{Xe}$ ). We report the Megadunes firn air isotopic ratios as the deviations from the surface values to account for possible (although small) drift of the firn air composition during the flask storage for $\sim 2 \mathrm{yr}$.

\section{Numerical model of firn air profiles}

To better understand the firn air data, finite-difference numerical simulations based on Eq. (1) are run that incorporate gravitational and thermal fractionation, with arbitrary parameters for eddy diffusivity and empirical estimates of effective molecular diffusivity found in an iterative procedure (Severinghaus et al., 2010). The advantage of this numerical approach is that it allows a more realistic representation of the actual diffusivities at the Megadunes site than would be possible with the simple theory, and allows us to test the hypothesis that kinetic fractionation occurs at the Megadunes site. The numerical model also contains a heat transport model that simulates temperature and thus thermal fractionation.

The effective molecular diffusivities were obtained in our previous work (Severinghaus et al., 2010) by trial-and-error fits of the forward model, forced with known atmospheric histories of $\mathrm{CO}_{2}$, methane, and halocarbons. The diffusivities of $\mathrm{CO}_{2}$ so derived are multiplied by the ratio of free-air diffusivities of each gas to $\mathrm{CO}_{2}$ (Table 3) to derive molecular diffusivities of each gas. Pressure and temperature effects on molecular diffusivity are treated as in Severinghaus and Battle (2006). 
Table 3. Gas parameters used in numerical model runs.

\begin{tabular}{lcccc}
\hline Gas pair & $\begin{array}{c}\text { Binary } \\
\text { molecular } \\
\text { diffusivity }\end{array}$ & $\begin{array}{c}\text { Mass } \\
\text { difference } \\
\left.\text { (ratio to } \mathrm{CO}_{2}\right)\end{array}$ & $\begin{array}{c}\text { Thermal diffusion } \\
\text { sensitivity }\end{array}$ \\
$\left(\mathrm{kg} \mathrm{mol}^{-1}\right)$ & \multicolumn{2}{c}{$\Omega\left(\% \circ \mathrm{K}^{-1}\right)$} \\
$b$
\end{tabular}

${ }^{1}$ binary molecular diffusivities are for a trace gas into air, not into ${ }^{28} \mathrm{~N}_{2}$, and are from the method of Fuller et al. as described by Reid et al. (1987). Air is treated for this purpose as having a mass of 0.029 and an effective molecular volume equal to the weighted average of the $\mathrm{N}_{2}$ and $\mathrm{O}_{2}$ volumes.

2 thermal diffusion sensitivity is given by $\Omega=a / T-b / T^{2}$, where $T$ is effective average temperature in Kelvin.

${ }^{3}$ Grachev and Severinghaus (2003b).

${ }^{4}$ Grachev and Severinghaus (2003a).

5 this work (Appendix C).

The model is forced at the surface with measured temperature from Automatic Weather Station data (Appendix B). The arbitrary eddy diffusivity is parameterized as an exponential in the top $24 \mathrm{~m}$, following Kawamura et al. (2006), with a linear taper to zero between 24 and $34 \mathrm{~m}$ (to avoid an artificial "step" at the bottom of the convection):

$$
\begin{array}{ll}
D_{\text {eddy }}=D_{\text {eddy }, 0} \exp \left(-\frac{z}{H}\right) & 0 \leq z \leq 24 \mathrm{~m} \\
D_{\text {eddy }}=D_{\text {eddy }, 24} \frac{34-z}{10} & 24 \leq z \leq 34 \mathrm{~m} \\
D_{\text {eddy }}=0 \quad z \geq 34 \mathrm{~m} &
\end{array}
$$

The arbitrary eddy diffusivity parameters are the surface value $D_{\text {eddy, } 0}$ and the scale depth $H$, and they are taken from our previous work (Severinghaus et al., 2010). As pointed out by Kawamura et al. (2006), these parameters are nonunique; different combinations of the two satisfy the deep profile data (see below). The near-surface data (top $15 \mathrm{~m}$ ) may constrain the solution further, because the amplitude of the seasonal thermal fractionation pulse (Fig. 3; Severinghaus et al., 2001 ) is sensitive to the value of $D_{\text {eddy, } 0 \text {. However, these }}$ near-surface data may reflect transient convective events in the previous few months prior to sampling, rather than longterm average conditions. Thus, any particular value of $H$ or $D_{\text {eddy, } 0}$ found by this method should be viewed as one of a range of possible values for the long-term (multi-year) average eddy diffusivity.

Furthermore, the exponential form of the eddy diffusivity is likely to be incorrect (Severinghaus et al., 2010), and a more accurate form of the eddy diffusivity would take into account permeability variations. At the present time we lack sufficient knowledge of the effective bulk permeability of the firn at the Megadunes site, due to the presence of large (multi-cm diameter) vertical cracks that greatly enhance air flow (Courville et al., 2007; Severinghaus et al., 2010). Thus, further refinement of the eddy diffusivity beyond the provisional estimates given here seems at present unjustified.

Thermal fractionation may contribute to the gas data (Fig. 3; see Sect. 5.2 for discussion), masking part of the effect of convection. To compute the eddy diffusivities accurately, therefore, Severinghaus et al. (2010) fitted the $\delta^{15} \mathrm{~N}$ and $\delta^{40} \mathrm{Ar} / 4$ data simultaneously, which required introduction of an arbitrary temperature gradient into the model (gravitational settling and convective mixing alone cannot reproduce the magnitude of the offset between the argon and nitrogen data, as they have similar molecular diffusivities). The eddy and molecular diffusivity profiles so found are given in Fig. 4, along with the Péclet number for $\delta^{15} \mathrm{~N}$.

In order to produce model estimates of $\mathrm{Kr}$ and $\mathrm{Xe}$ isotopes, the thermal diffusion sensitivities of these pairs are needed. Prior to this work, these had never been measured in air, and air coefficients are different from those in pure gases due to the fact that collisions in air are mostly with $\mathrm{N}_{2}$ and $\mathrm{O}_{2}$ (Grachev and Severinghaus, 2003a). For this reason, we measured them by equilibrating air in a known temperature gradient in the laboratory, following established procedures (Grachev and Severinghaus, 2003b). Details are given in Appendix C. The resulting $\Omega$ values are shown in Table 3, and the following parameterizations are obtained.

$$
\begin{array}{lll}
{ }^{86} \mathrm{Kr} /{ }^{82} \mathrm{Kr} & \Omega=5.05 / T_{\mathrm{K}}-580 /\left(T_{\mathrm{K}}\right)^{2} & \% \mathrm{~K}^{-1} \\
{ }^{136} \mathrm{Xe} /{ }^{129} \mathrm{Xe} & \Omega=11.07 / T_{\mathrm{K}}-2000 /\left(T_{\mathrm{K}}\right)^{2} & \% \circ \mathrm{K}^{-1}
\end{array}
$$

As discussed above, the trace gas is run against "29air", so the appropriate coefficient should be the $\Omega$ value for ${ }^{86} \mathrm{Kr} /{ }^{29}$ air. For simplicity, however, this value of $\Omega$ was not computed; instead an approximation was made in which $\Omega$ for ${ }^{86} \mathrm{Kr} /{ }^{82} \mathrm{Kr}$ was assigned to the ${ }^{86} \mathrm{Kr} /{ }^{29}$ air run, and a value of zero was assigned to the ${ }^{82} \mathrm{Kr} /{ }^{29}$ air run, following Severinghaus et al. (2010). Because the temperature signals are small, this approximation introduced negligible error.

\section{Results and discussion}

\subsection{Theoretical values of kinetic fractionation}

Numerical integration of the Péclet number profile (Fig. 4) allows computation of the expected kinetic fractionation at the Megadunes site using the simple theory (Eqs. 9 and 10). In this exercise, we slightly modified the eddy diffusivity profile of Severinghaus et al. (2010) to make it steady in time ( $H$ and $D_{\text {eddy, } 0}$ are $11.5 \mathrm{~m}$ and $1.6 \times 10^{-4} \mathrm{~m}^{2} \mathrm{~s}^{-1}$, respectively). The value obtained for the xenon-nitrogen fractionation $\left(\varepsilon_{136-129}\right)$ is $-0.013 \%$. In other words, the expected 


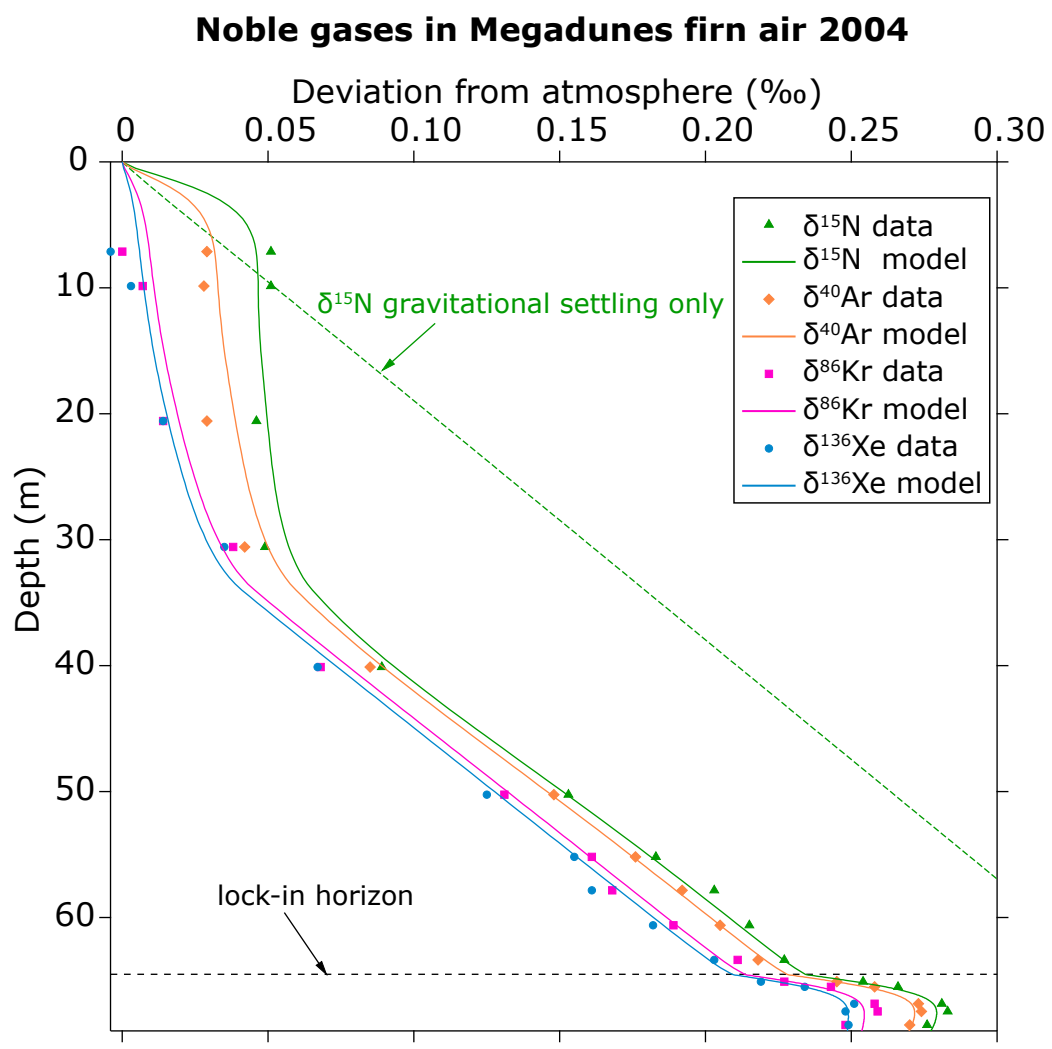

Fig. 3. Observed inert gas ratios in firn air at the Megadunes site, East Antarctica, January 2004. Values are averaged for each depth where replicate measurements are made. To facilitate comparison, $\delta$ values are normalized by dividing by the mass difference. The lock-in horizon depth of $64.5 \mathrm{~m}$ is found from measured $\mathrm{CO}_{2}$ and $\mathrm{CH}_{4}$ data. Model results are for a surface eddy diffusivity of $1.6 \times 10^{-4} \mathrm{~m}^{2} \mathrm{~s}^{-1}$ and scale depth $H$ of $5.9 \mathrm{~m}$ in deep part of lock-in zone, increasing in upper part of lock-in zone in order to fit the data. This implies a deepening of convection through time, modeled as starting in 1934 C.E. and reaching the full depth of $H=12.2 \mathrm{~m}$ in 2004 C.E.

value for $\delta^{136} \mathrm{Xe} /{ }^{129} \mathrm{Xe}$ would be $7 \times 0.013=0.093 \%$ less than $7 \times \delta^{15} \mathrm{~N}$. Likewise, the krypton-nitrogen fractionation $\left(\varepsilon_{86}-82\right)$ is $-0.011 \%$. For argon-nitrogen $\left(\varepsilon_{40-36}\right)$ the value is much smaller, $-0.002 \%$, as expected due to the similar diffusivities of $\mathrm{Ar}$ and $\mathrm{N}_{2}$. These values apply to the depth interval between 34 and $64 \mathrm{~m}$ (pure "diffusive zone"), due to the fact that the eddy diffusivity is set to zero in this interval.

These values can be directly compared with the modeled difference between Xe and $\mathrm{N}_{2}$ isotopes, run with thermal fractionation set to zero, which is $-0.015 \%$ o $(-0.012$ for $\mathrm{Kr}$, and -0.002 for Ar). This good agreement confirms that the simple theory and numerical simulation reproduce the same essential physics by very different means and are consistent. Note that the method for finding eddy diffusivities does not make use of $\mathrm{Kr}$ or Xe data. Thus, the fit of model and data for $\mathrm{Kr}$ and $\mathrm{Xe}$ can now be used to independently test the hypothesis that kinetic fractionation occurs at the Megadunes site.

\subsection{Megadunes isotopic data and simulation}

Results of the isotopic ratios are averaged for each depth and presented versus depth, normalized by the mass difference
$\Delta M$ for visual comparison (Fig. 3). As expected from theory, normalized $\mathrm{Kr}$ and $\mathrm{Xe}$ isotopes are less enriched in the firn air column than $\mathrm{N}_{2}$ and Ar isotopes, and these differences extend throughout the column indicating that it is not a temporary phenomenon (because the mixing time for air in the deep firn is order $5 \mathrm{yr}$ ). This finding generally confirms the theory, and is the main result of this work.

A numerical simulation aids in the interpretation of the data, and the results are also shown in Fig. 3. We first simulate the firn air isotopic profiles using the model setup employed by Severinghaus et al. (2010). In that work, the surface eddy diffusivity was $D_{\text {eddy, } 0}=1.6 \times 10^{-4} \mathrm{~m}^{2} \mathrm{~s}^{-1}$ at all times, and the scale depth $H$ increased with time from a value of $5.9 \mathrm{~m}$ prior to 1934 C.E. to $12 \mathrm{~m}$ at the time of sampling, to simulate gradual deepening of convection and to adequately reproduce the data in the lock-in zone. Note that the $\mathrm{N}_{2}$ and Ar isotopes slightly disagree (Fig. 3) probably because a small amount of thermal fractionation has affected the gases (Severinghaus et al., 2010). This thermal fractionation effect must be taken into account in model simulations or data analyses to quantify kinetic effects, because $\mathrm{Kr}$ and $\mathrm{Xe}$ are less sensitive to thermal effects than $\mathrm{N}_{2}$ (Grew 


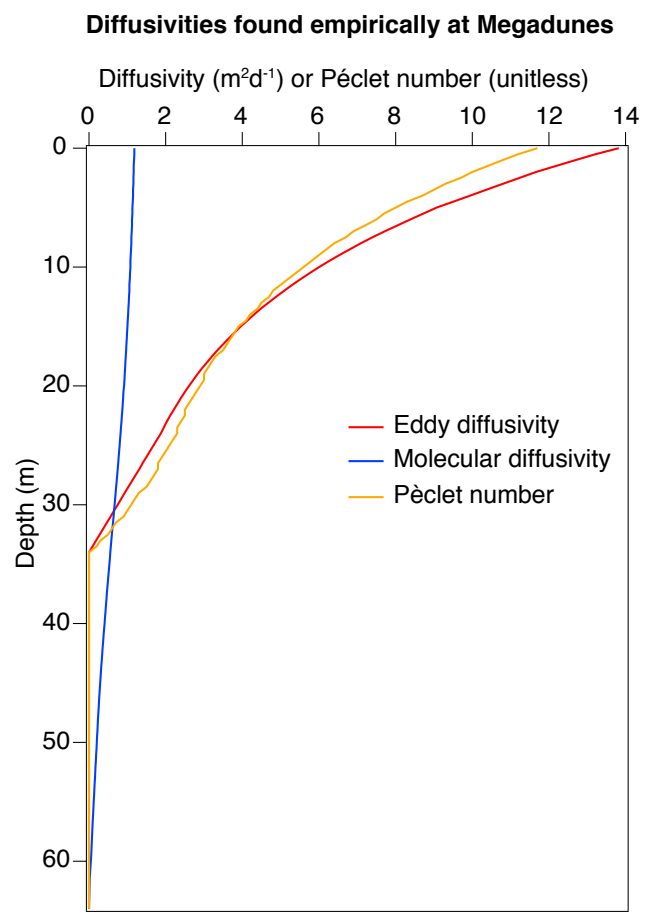

Fig. 4. Depth profiles of transport parameters found at Megadunes by fitting to data. Eddy diffusivities and molecular diffusivities are in units of $\mathrm{m}^{2} \mathrm{day}^{-1}$ for ease of comparison with the Péclet number. Numerical integration of this Péclet number allows calculation of the kinetic fractionation via the simple theory.

and Ibbs, 1952). The temperature gradient is assumed to be $0.0028^{\circ} \mathrm{C} \mathrm{m}^{-1}\left(\sim 1^{\circ} \mathrm{C}\right.$ between top and bottom of diffusive zone) to represent the thermal effects (see Severinghaus et al., 2010 for further discussion).

Using the molecular diffusivities and newly measured thermal diffusion sensitivities for $\mathrm{Kr}$ and $\mathrm{Xe}$ (Table 3), the modeled $\delta^{86} \mathrm{Kr}$ and $\delta^{136} \mathrm{Xe}$ agree with the data fairly well. The average differences between data and model, averaged over three depths $(50.24,55.17$ and $60.61 \mathrm{~m})$, are +0.002 , $0.000,-0.001$ and $-0.003 \%$ for $\delta^{15} \mathrm{~N}, \delta^{40} \mathrm{Ar} / 4, \delta^{86} \mathrm{Kr} / 4$ and $\delta^{136} \mathrm{Xe} / 7$, respectively, and they are within the measurement uncertainties. We limit the data-model comparison to this depth range because the shallower data may contain thermal signals from seasonal temperature variations at the surface and the deeper data may contain signals of the transient change in the convective zone. We also omit the data at $57.83 \mathrm{~m}$ from this and following analyses because $\delta^{15} \mathrm{~N}$, $\delta^{86} \mathrm{Kr}$ and $\delta^{136} \mathrm{Xe}$ at this depth strongly deviate, with different signs, from those expected from the adjacent data, suggesting errors during sampling or measurements.

Because of thermal effects, the differences between gases are larger than expected for kinetic fractionation alone (for example, modeled $\delta^{86} \mathrm{Kr} / 4-\delta^{15} \mathrm{~N}$ is $-0.022 \%$ versus $\varepsilon_{86-82}=-0.012 \%$, and modeled $\delta^{136} \mathrm{Xe} / 7-\delta^{15} \mathrm{~N}$ is -0.027 $\%$ versus $\varepsilon_{136-129}=-0.015 \%$ ). Thus, at least three sepa- rate gas species isotope ratios are needed to characterize the convective zone, diffusive zone and thermal signal. The $\mathrm{N}_{2}$ and $\mathrm{Ar}$ isotopes are useful for constraining the thermal effects, because they have very similar molecular diffusivities but different thermal diffusion sensitivities. We corrected the data for thermal effects using the following equation (Severinghaus et al., 2010):

$\delta_{\text {grav }}=\delta_{\text {obs }}-\frac{\delta^{15} \mathrm{~N}_{\mathrm{obs}}-\left(\delta^{40} \mathrm{Ar}_{\mathrm{obs}} / 4-\varepsilon_{40-36}\right)}{\Omega^{15}-\Omega^{40} / 4} \times \Omega$

where $\delta_{\text {grav }}$ is the pure gravitational component, $\delta_{\text {obs }}$ is the measured value, $\varepsilon_{40-36}$ is $-0.002 \%$ for the Megadunes site (see above), $\left(\Omega^{15}-\Omega^{40} / 4\right)$ is $+0.0047 \% \mathrm{~K}^{-1}$ (Grachev and Severinghaus, 2003a, b) and $\Omega$ is thermal diffusion sensitivity (Table 3 ). The kinetic fractionations $\varepsilon_{86-82}$ and $\varepsilon_{136-129}$ thus estimated from the data for the deep firn are -0.010 and $-0.015 \%$, respectively, in excellent agreement with the model-derived values. The fit of the model and data demonstrate that kinetic fractionation occurs at the Megadunes site and that they are measurable with our precision.

Near-surface isotopic values give some constraint on the convection parameters $D_{\text {eddy, } 0}$ (and $H$ ) for modern firn air sites, as discussed above. However, no data is available in ice core gases to directly constrain these parameters in the past firn. Thus, the success of an ice-core proxy of the convective zone partly depends on the insensitivity of kinetic fractionation in deep firn to different combinations of $D_{\text {eddy, } 0}$ and $H$. In order to investigate this, we ran the model with several values of $D_{\text {eddy, } 0}\left(0.6,1.0,1.6\right.$ and $\left.4.0 \times 10^{-4} \mathrm{~m}^{2} \mathrm{~s}^{-1}\right)$, while adjusting $H$ to match $\delta^{15} \mathrm{~N}$ in deep firn within $0.001 \%$ (following Kawamura et al., 2006). Thermal effects are included as in the standard model runs. Unlike the standard runs, the values of $D_{\text {eddy, } 0}$ and $H$ are kept constant in time. The results are shown in Fig. 5 and compared with the firn air data. The values of $\delta^{86} \mathrm{Kr} / 4-\delta^{15} \mathrm{~N}(-0.024,-0.023,-0.022$ and $-0.020 \%$ ) and $\delta^{136} \mathrm{Xe} / 7-\delta^{15} \mathrm{~N}(-0.030,-0.028,-0.027$ and $-0.024 \%$ ) for different combinations are similar to each other, and thus show that the kinetic fractionation is rather insensitive to the (poorly known) exact values of $D_{\text {eddy, } 0}$ and $H$.

In a first-order approximation in which $\varepsilon$ and convective zone thickness are linearly related, the maximum spreads of isotopic differences from the above exercise $( \pm 0.002$ and \pm 0.003 per mil for the $\mathrm{Kr}-\mathrm{N}_{2}$ and $\mathrm{Xe}-\mathrm{N}_{2}$ pairs, respectively) would result in an uncertainty of $\pm \sim 4 \mathrm{~m}$ in convective zone thickness. This magnitude of uncertainty is acceptable to test the existence of a $\sim 30-40-\mathrm{m}$ convective zone in glacial periods by ice-core measurements. A more significant source of uncertainty is the measurement precision of the $\mathrm{Kr}$ and $\mathrm{Xe}$ isotopes (currently $0.004 \%$ as one standard deviation when normalized), giving uncertainty in convective zone thickness on the order of $20 \%$ for a $40-\mathrm{m}$ convective zone if we use one data point. With the current precisions, it will be desired to measure and average several data points from similar depth (age) in future ice-core studies. 

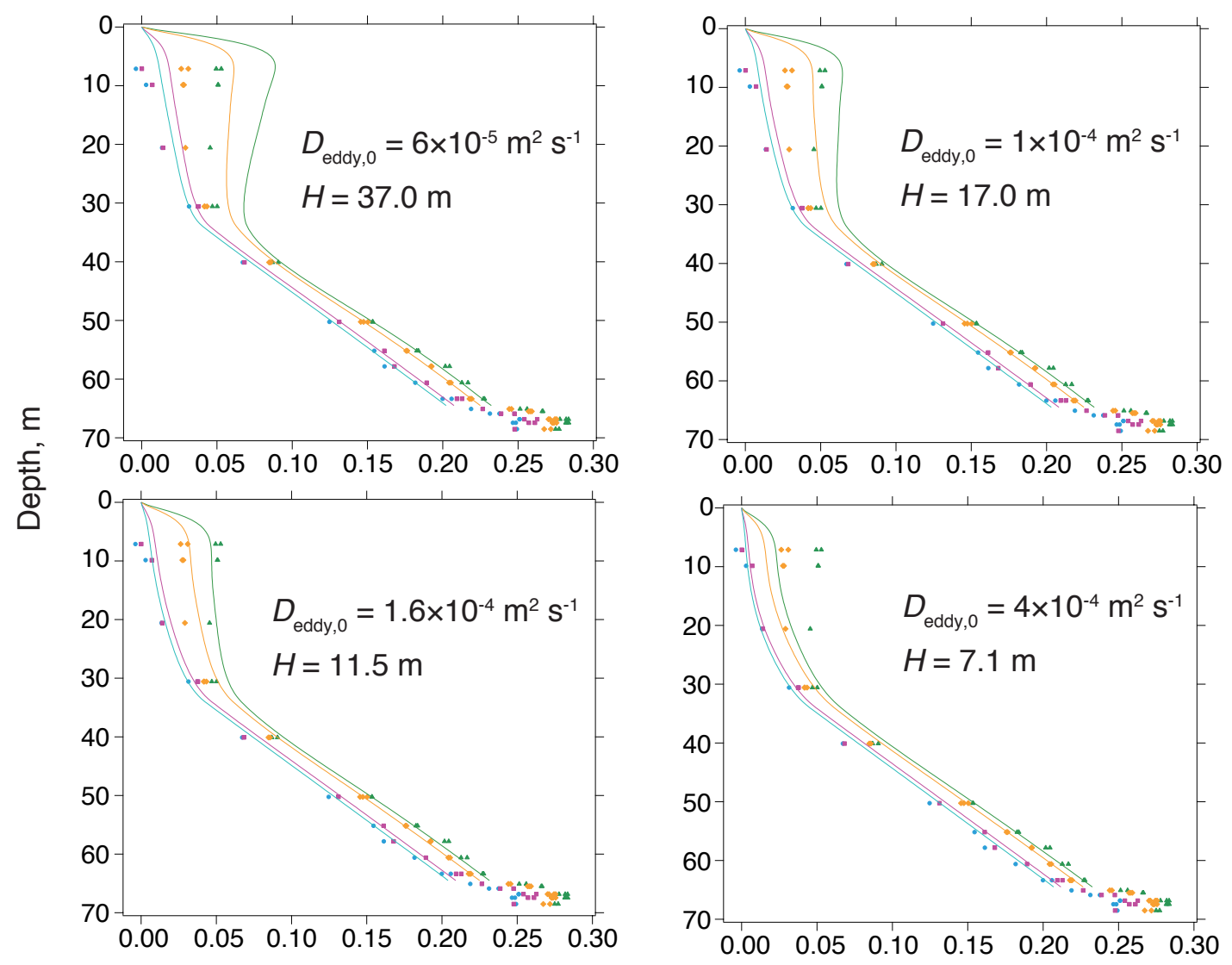

Isotopic ratios (\%o)

Fig. 5. Model results with different combinations of surface eddy diffusivity and scale depth. The eddy diffusivity profiles were kept constant in time for all cases.

Improved constraints on the near-surface eddy diffusivity would reduce uncertainty associated with the calibration of $\varepsilon$ for convective zone thickness especially for Xe. The standard value of $D_{\text {eddy, } 0}\left(1.6 \times 10^{-4} \mathrm{~m}^{2} \mathrm{~s}^{-1}\right)$ that best reproduces the near-surface gas profiles at the Megadunes site (convective zone $\sim 23 \mathrm{~m})$ is larger than those $\left(4-6 \times 10^{-5} \mathrm{~m}^{2} \mathrm{~s}^{-1}\right)$ at Dome Fuji (convective zone $\sim 9 \mathrm{~m}$ ) and YM85 (convective zone $\sim 14 \mathrm{~m}$ ) (Kawamura et al., 2006; Severinghaus et al., 2010). With more data from different sites, it might be possible in the future to parameterize the near-surface eddy diffusivity with climatic parameters such as accumulation rate, which can be estimated from ice cores.

Quantifying kinetic effects will also be valuable for reconstructing past mean ocean temperature using past atmospheric $\mathrm{Kr}$ and Xe burdens inferred from trapped air in ice cores (Headly and Severinghaus, 2007). As a test, we attempted to reconstruct the atmospheric $\mathrm{Kr} / \mathrm{N}_{2}$ and $\mathrm{Xe} / \mathrm{N}_{2}$ ratios from the deep firn air sampled at the Megadunes site, using only those parameters that would be available in an ice core study. If our method for making fractionation corrections is successful, we should obtain a value of zero for $\delta \mathrm{Kr} / \mathrm{N}_{2}$ and $\delta \mathrm{Xe} / \mathrm{N}_{2}$, as the atmosphere cannot have changed significantly on this $\sim 5 \mathrm{yr}$ time scale (Keeling et al., 2004).

Without including kinetic effects, $\delta^{84} \mathrm{Kr} / \mathrm{N}_{2}=-0.40 \%$ o and $\delta^{132} \mathrm{Xe} / \mathrm{N}_{2}=-0.89 \%$ for the average of the four depths between 50 and $60 \mathrm{~m}$ depth ( $n=8$ flasks), after thermal and gravitational corrections using $\mathrm{N}_{2}$ and Ar isotope data. We then accounted for kinetic effects using the simple theory to relate the magnitude of elemental fractionation to measured isotopic fractionation, and obtained $\delta^{84} \mathrm{Kr} / \mathrm{N}_{2}=-0.08 \%$ and $\delta^{132} \mathrm{Xe} / \mathrm{N}_{2}=-0.02 \%$. These values are equal to zero within measurement uncertainties (on the order of 0.2 and $0.4 \%$, respectively; Severinghaus et al., 2001; Headly and Severinghaus, 2007) and constitute a successful test of the method, in addition to demonstrating the value of accounting for kinetic effects on the heavy noble gases in air from ice cores.

\section{Conclusions}

First principles predict that kinetic fractionation of gas isotopes occurs in firn when convection is intense near the surface. By establishing novel high-precision analytical meth- 


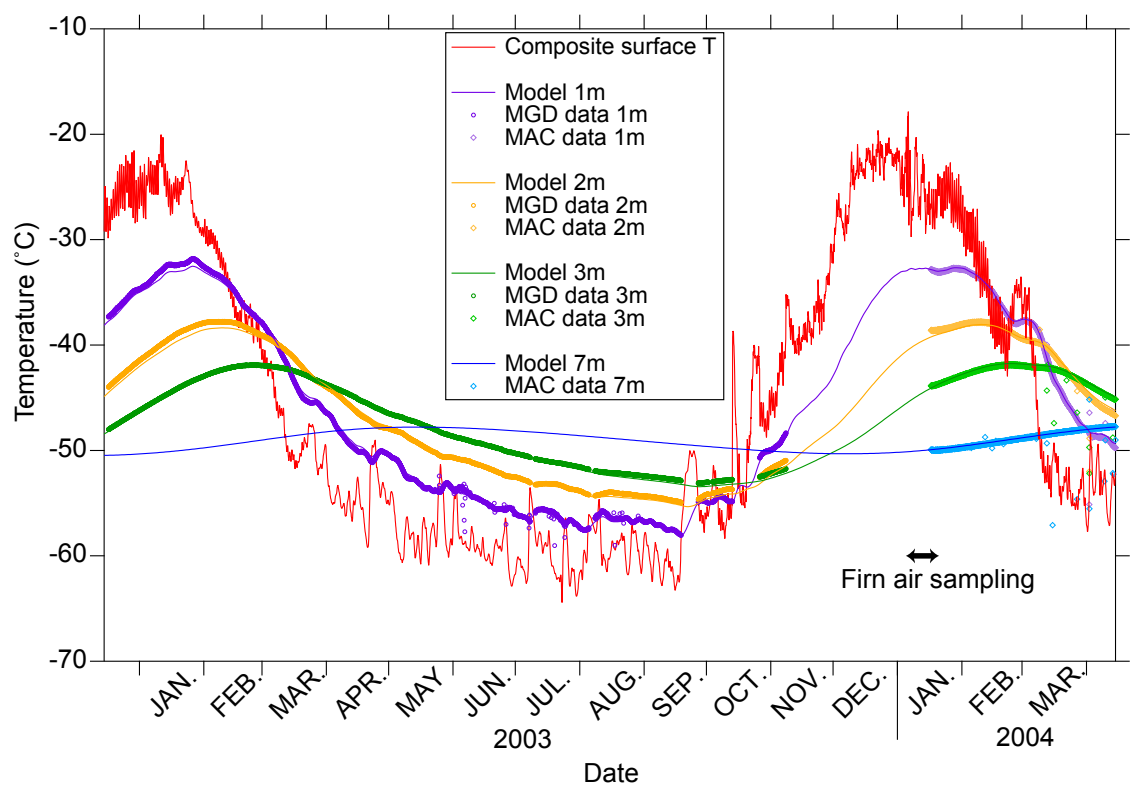

Fig. A1 Temperature observations and model results used to create composite surface temperature history for gas model forcing. Data from the first Megadunes AWS (MGD) has gaps around September and October 2003 and November 2003-January 2004 due to instrument failure. Data from the Henry AWS were used to splice together a composite record, with small adjustments made to fit the subsurface temperature observations. Since January 2004 the MAC AWS data from Megadunes are shown. Note that there are up to a few dozens of data points per day, thus they mostly appear as thick lines in the figure.

ods for isotopic ratios of the heavy noble gases $\mathrm{Kr}$ and $\mathrm{Xe}$, we have demonstrated that kinetic fractionation does occur in Nature. Further, the observed amounts of kinetic fractionation for $\mathrm{Kr}$ and $\mathrm{Xe}$ isotopes are consistent with numerical model predictions. Different eddy diffusivity parameterizations, in which the overall thickness of the convective zone is kept constant, yield similar kinetic fractionations, which is encouraging for the prospects of developing proxy indicators of past convective zone thickness. Therefore, these results suggest that it may be feasible to evaluate the hypothesis that very deep convection (up to $\sim 40 \mathrm{~m}$ ) occurred preferentially during the glacial periods, by using future ice-core measurements. Toward this aim, further work is needed to establish methods and conduct high-precision ice-core measurements of $\mathrm{Kr}$ and/or Xe isotopes, as well as modeling exercises for calibrating the gas records to the depth of convection.

Using this convection indicator, it should also be possible to correct for the effect of convection on the ice core Xe/ $/ \mathrm{N}_{2}$ and $\mathrm{Kr} / \mathrm{N}_{2}$ ratios, which are being developed as indicators of past mean ocean temperature based on solubility effects (Headly and Severinghaus, 2007; Ritz et al., 2011). Quantifying past convection will also strengthen estimates of past temperature change in Antarctic records and associated phasing of greenhouse gas variations with climate (Caillon et al., 2003; Landais et al., 2006; Parrenin et al., 2012, 2013). Finally, enigmatic intervals of near-zero gravitational fractionation, seen in several Antarctic ice core $\mathrm{Ar}$ and $\mathrm{N}_{2}$ isotope records (Severinghaus et al., 2003), may be due to deep convection enabled by mechanical disruption (crevassing or cracking) of the firn. A paleo-convection proxy would allow a decisive test of this hypothesis.

\section{Appendix A}

\section{Exact treatment of simple theory}

The commonly used $\delta$ parameter is cumbersome to treat exactly, so here we use the sample-to-standard ratio of gas ratios, also known as the separation factor $q$ :

$q \equiv \frac{R_{\text {sample }}}{R_{\text {standard }}}=\delta / 1000+1$

A kinetic fractionation factor $\alpha_{\mathrm{k}}$ is defined as the ratio of an actual isotope pair $x$, in a convecting system, to the value of the isotope pair without kinetic fractionation. Thus for the case of no kinetic fractionation, $\alpha=1$. The separation factor $q$ of the ${ }^{15} \mathrm{~N} /{ }^{14} \mathrm{~N}$ isotope pair can be used as a close proxy for this expected value (although it will have slight fractionation):

$\alpha_{\mathrm{k}} \equiv \frac{q_{x}}{q_{15 / 14} \mathrm{~N}}$

For simplicity, this equation only describes an isotope pair $x$ having a one mass-unit difference, the same as the ${ }^{15} \mathrm{~N} /{ }^{14} \mathrm{~N}$ isotope pair. The equation can be generalized to any mass 


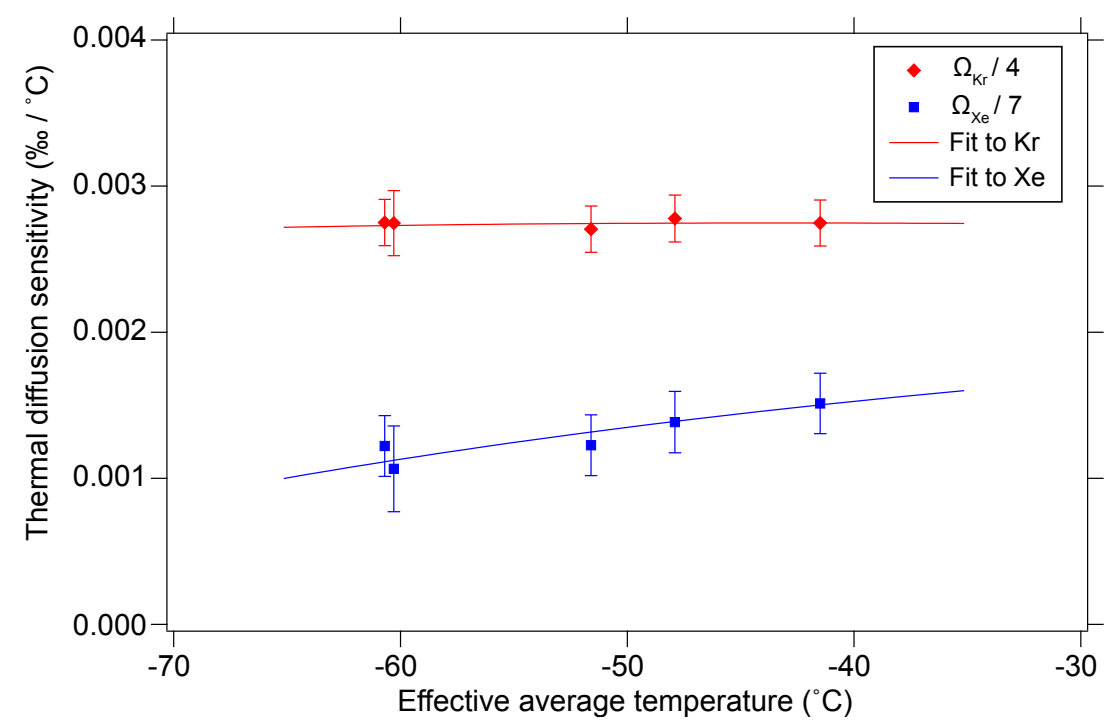

Fig. A2 Laboratory results of thermal diffusion coefficient measurements made in this study for the isotope pairs ${ }^{86} \mathrm{Kr} /{ }^{82} \mathrm{Kr}$ and ${ }^{136} \mathrm{Xe} /{ }^{129} \mathrm{Xe}$. Values are normalized by the mass difference for ease of comparison. Curve fits shown are $\Omega=5.05 / T-580 / T^{2}$ and $\Omega=11.07 / T-2000 / T^{2} \% \mathrm{~K}^{-1}$ for $\mathrm{Kr}$ and Xe, respectively (curve coefficients are actual values, not normalized). Error bars represent expected error ( \pm one standard deviation) based on the reproducibility of control measurements (including machine precision and gas handling error). Fluctuation of temperature during the thermal diffusion measurements contributes little $(<1 \%)$ to the uncertainty of $\Omega$ owing to the large temperature differences $(\sim 30-40 \mathrm{~K})$ employed in the experiments.

Table A1. Thermal diffusion coefficients for $\mathrm{Kr}$ and $\mathrm{Xe}$.

\begin{tabular}{cccccccccc}
\hline$T_{\text {cold }}$ & $T_{\text {hot }}$ & $T_{\text {ave }}$ & $\Delta T$ & $\delta^{86} \mathrm{Kr}$ & $\Omega_{\mathrm{Kr}}$ & error & $\delta^{136} \mathrm{Xe}$ & $\Omega_{\mathrm{Xe}}$ & error \\
\hline-60.4 & -20.2 & -41.5 & 40.2 & 0.442 & 0.0110 & 0.0006 & 0.426 & 0.0106 & 0.0014 \\
-66.5 & -27.1 & -47.9 & 39.4 & 0.438 & 0.0111 & 0.0006 & 0.382 & 0.0097 & 0.0015 \\
-70.3 & -30.4 & -51.6 & 39.9 & 0.432 & 0.0108 & 0.0006 & 0.343 & 0.0086 & 0.0015 \\
-73.8 & -45.5 & -60.3 & 28.3 & 0.311 & 0.0110 & 0.0009 & 0.211 & 0.0075 & 0.0021 \\
-79.4 & -39.5 & -60.7 & 39.9 & 0.439 & 0.0110 & 0.0006 & 0.341 & 0.0086 & 0.0015 \\
\hline
\end{tabular}

$T_{\text {ave }}$ refers to the effective average temperature (Grachev and Severinghaus, 2003a).

difference by noting that gravitational fractionation increases in proportion to the mass difference $\Delta m$ :

$q_{x}=e^{\Delta m_{x} g z / R T}$

For a gas pair $y$ having a larger mass difference:

$\frac{\ln \left(q_{x}\right)}{\ln \left(q_{y}\right)}=\frac{\Delta m_{x}}{\Delta m_{y}} \equiv R_{\Delta m}$

This allows us to normalize the separation of an isotope pair $y$ to the value for a one mass-unit difference, using the ratio of the mass differences $R_{\Delta m}$ :

$q_{x}=q_{y}^{R_{\Delta m}}$

$\alpha_{y} \equiv \frac{q_{y}^{R_{\Delta m}}}{q_{15 / 14 \mathrm{~N}}}$

Or, for convenience, the $\log$ of $\alpha$ can be used to describe the fractionation, which we call $\varepsilon^{\prime}$ to distinguish it from the epsilon used above in the approximate theory:

$\varepsilon_{y}^{\prime} \equiv \ln \alpha_{y}=R_{\Delta m} \ln q_{y}-\ln q_{15 / 14} \mathrm{~N}$

The exact separation factor in a situation where thermal diffusion is neglected would be:

$q_{y}(z)=\int_{0}^{z^{\prime}} \frac{\Delta m_{y} g /(R T) q_{y}}{1+P e_{y}(z)} \mathrm{d} z+q(0)$

The $q$ term in the integrand makes this an ordinary differential equation (ODE). This term was neglected in the prior approximation, but can have values as large as 1.06 for the $\mathrm{Xe}-\mathrm{N}_{2}$ pair in a $100-\mathrm{m}$ deep firn column. The value of $q$ at the surface, $q(0)$, is 1 because of our definition of $q$. The predicted fractionation factor $\alpha$ of a gas pair $y$ may now be 
written exactly as:

$\alpha_{y}=\frac{\left(\int_{0}^{z^{\prime}} \frac{\Delta m_{y} g /(R T) q_{y}}{1+P e_{15}(z) \frac{D_{15}}{D_{y}}} \mathrm{~d} z+1\right)^{R_{\Delta m}}}{\int_{0}^{z^{\prime}} \frac{\Delta m_{15} g /(R T) q_{15}}{1+P e_{15}(z)} \mathrm{d} z+1}$

Here the $D_{15}$ refers to the binary molecular diffusivity of ${ }^{15} \mathrm{~N}^{14} \mathrm{~N}$ into air, and the $P e_{15}$ is the ratio of the eddy diffusivity to the molecular diffusivity of ${ }^{15} \mathrm{~N}^{14} \mathrm{~N}$ into air in the porous medium (the Péclet number). In natural systems the Péclet number is typically a complicated function of depth, and so the expression is not easily integrated, and must be numerically approximated.

In the special case where the Péclet number is constant with depth (clearly not very realistic), the ODE is easily solved:

$q_{y}(z)=\exp \left(\frac{\Delta m_{y} g /(R T)}{1+P e_{y}} z\right)$

and the expression for the fractionation simplifies to:

$\alpha_{y}=\frac{\left(\exp \left(\frac{\Delta m_{y} g z / R T}{1+P e_{15} \frac{D_{15}}{D_{y}}}\right)\right)^{R_{\Delta m}}}{\exp \left(\frac{\Delta m_{15} g z / R T}{1+P e_{15}}\right)}$
$=\exp \left(\frac{\Delta m_{15} g z}{R T}\left[\frac{1}{1+P e_{15} \frac{D_{15}}{D_{y}}}-\frac{1}{1+P e_{15}}\right]\right)$

$\varepsilon_{y}^{\prime}=\ln \alpha_{y}=\frac{\Delta m_{15} g z}{R T}\left[\frac{1}{1+P e_{15} \frac{D_{15}}{D_{y}}}-\frac{1}{1+P e_{15}}\right]$

Note that Eq. (A12), which is exact, is identical to Eq. (9) under the same assumption of constant $P e$ with depth, except that $\varepsilon^{\prime} \equiv \ln \alpha$ is used instead of $\varepsilon \equiv \alpha-1$.

\section{Appendix B}

\section{Surface temperature observations used to force model}

Automatic weather station (AWS) data are available for part of the year prior to sampling at the Megadunes site, from a station deployed by M. Fahnestock and T. Scambos in November 2002 (Fig. A1; denoted MGD). This station measured firn temperatures at several depths in addition to surface temperature, wind speed, barometric pressure, and other meteorological variables. In the extreme cold of late winter 2003, the AWS failed intermittently so no data are available for some intervals. During these intervals, a composite Megadunes surface temperature record was created using AWS air temperature data from a site near South Pole (Henry
AWS, $89.01^{\circ} \mathrm{S} 1.03^{\circ} \mathrm{W}, 2755$ m elevation a.s.1.), which empirically tracked Megadunes temperature very closely in the periods in which both stations were functioning. Firn temperature at Megadunes from 1, 2, and $3 \mathrm{~m}$ depth was used to verify the composite record, taking advantage of the fact that diffusive propagation of heat through firn causes characteristic time lags that increase with depth. The numerical heat diffusion model was used to predict temperature at these three depths, for comparison with the data (Fig. A1). In several intervals the model run with Henry data produced mismatches with the Megadunes data, and in these intervals the composite record was manually adjusted to produce a match with the Megadunes subsurface data. After sampling firn air, a second AWS was deployed (denoted MAC) and this data record was used to further verify the method used to create the composite record. To mimic the seasonal cycle prior to the availability of data in 2002, an idealized seasonal temperature history (Severinghaus et al., 2001) with mean annual temperature of $-49^{\circ} \mathrm{C}$ was used to force the gas model.

\section{Appendix C}

\section{Laboratory measurement of thermal diffusion coefficients for $\mathrm{Kr}$ and $\mathrm{Xe}$}

Standard procedures (Grachev and Severinghaus, 2003a, b) were used with the following modifications. Ambient air was sampled in a 2-L glass flask at $\sim 1$ atm and then doped with pure $\mathrm{Kr}$ and $\mathrm{Xe}$ so that their concentrations became $\sim 30$ times the atmospheric values. This was necessary to obtain sufficient $\mathrm{Kr}$ and $\mathrm{Xe}$ signals for mass spectrometer measurements using a small gas container for the thermal fractionation experiments (having two chambers of $\sim 26 \mathrm{~mL}$ each in series). The doping is not expected to influence the results because $\mathrm{Kr}$ and $\mathrm{Xe}$ concentrations are so low that they still collide dominantly with major gases $\left(\mathrm{N}_{2}, \mathrm{O}_{2}\right.$ and $\left.\mathrm{Ar}\right)$. The air was subsampled into one of the two connected chambers at $\sim 1$ atm, expanded to the other chamber (so the total pressure became $\sim 0.5 \mathrm{~atm})$, and then equilibrated under a large temperature difference $\left(\sim 30\right.$ to $\left.40^{\circ} \mathrm{C}\right)$ at different average temperature $\left(\sim-40\right.$ to $\left.-60^{\circ} \mathrm{C}\right)$ for $4 \mathrm{~h}$ (Table A1), with a valve between the two chambers open to allow diffusive transport. The temperature of each chamber was controlled within $0.3^{\circ} \mathrm{C}$ (one standard deviation). After the equilibration, the valve between the two chambers was closed to separate them. Noble gases in each chamber were extracted with the standard procedure as used for the firn air samples, and then pure Ar was added to increase the total gas amount similar to that of typical firn air measurements. The isotopic ratios ${ }^{86} \mathrm{Kr} /{ }^{82} \mathrm{Kr}$ and ${ }^{136} \mathrm{Xe} /{ }^{129} \mathrm{Xe}$ from the "cold" chamber were measured against those from the "warm" chamber. Four control runs were made with the same procedures but using an isothermal water bath at room temperature (Grachev and Severinghaus, 2003a, b), producing the results 
of $+0.024 \pm 0.025 \%$ and $-0.013 \pm 0.058 \%$ o for ${ }^{86} \mathrm{Kr} /{ }^{82} \mathrm{Kr}$ and ${ }^{136} \mathrm{Xe} /{ }^{129} \mathrm{Xe}$, respectively. Results (Table A1 and Fig. A2) were fitted with a quadratic function (Grachev and Severinghaus, 2003a, b). The uncertainties in temperature and isotopic measurement are taken into account for the error estimates.

Acknowledgements. Michael Bender made the nitrogen isotope measurements. Helpful discussions with Ralph Keeling, Bruce Cornuelle, and Bill Young improved the manuscript. We thank the Megadunes Field Team and NY Air National Guard for field support, and the Light Ground Traverse 2003-2004 for preparing the skiway that enabled LC-130 landings at the Megadunes site. Louise Albershardt of Ice Drilling and Design Operations group (IDDO) did the drilling. K. Kawamura acknowledges Fuyuki Saito of JAMSTEC and Jun'ichi Okuno of NIPR for assisting LaTeX editing. Support for this work came from NSF-OPP 02-30452 (J. P. Severinghaus), Gary Comer Abrupt Climate Change Fellowship (for supporting K. Kawamura as a postdoc at SIO) and JSPS KAKENHI 21671001 (K. Kawamura). The production of the paper was supported by an NIPR publication subsidy.

\section{References}

Albert, M. R.: Modeling heat, mass, and species transport in polar firn, Ann. Glaciol., 23, 138-143, 1996.

Albert, M. R. and Shultz, E.: Snow and firn properties and air-snow transport processes at Summit, Greenland, Atmos. Environ., 36, 2789-2797, doi:10.1016/S1352-2310(02)00119-X, 2002.

Albert, M. R., Shuman, C., Courville, Z., Bauer, R., Fahnestock, M., and Scambos, T.: Extreme firn metamorphism: impact of decades of vapor transport on near-surface firn at a low-accumulation glazed site on the East Antarctic plateau, Ann. Glaciol., 39, 7378, doi:10.3189/172756404781814041, 2004.

Battle, M. L., Bender, M., Sowers, T., Tans, P. P., Butler, J. H., Elkins, J. W., Ellis, J. T., Conway, T., Zhang, N., Lang, P., and Clarke, A. D.: Atmospheric gas concentrations over the past century measured in air from firn at the South Pole, Nature, 383, 231-235, doi:10.1038/383231a0, 1996.

Bender, M. L., Sowers, T., Barnola, J. M., and Chappellaz, J.: Changes in the $\mathrm{O}_{2} / \mathrm{N}_{2}$ ratio of the atmosphere during recent decades reflected in the composition of air in the firn at Vostok station, Antarctica, Geophys. Res. Lett., 21, 189-192, doi:10.1029/93gl03548, 1994a.

Bender, M. L., Tans, P. P., Ellis, J. T., Orchardo, J., and Habfast, $\mathrm{K}$.: A high-precision isotope ratio mass spectrometry method for measuring the $\mathrm{O}_{2} / \mathrm{N}_{2}$ ratio of air, Geochim. Cosmochim. Ac., 58, 4751-4758, doi:10.1016/0016-7037(94)90205-4, 1994b.

Bender, M. L., Ho, D. T., Hendricks, M. B., Mika, R., Battle, M. O., Tans, P. P., Conway, T. J., Sturtevant, B., and Cassar, N.: Atmospheric $\mathrm{O}_{2} / \mathrm{N}_{2}$ changes, 1993-2002: Implications for the partitioning of fossil fuel $\mathrm{CO}_{2}$ sequestration, Global Biogeochem. Cy., 19, GB4017, doi:10.1029/2004gb002410, 2005.

Bender, M. L., Floch, G., Chappellaz, J., Suwa, M., Barnola, J. M., Blunier, T., Dreyfus, G., Jouzel, J., and Parrenin, F.: Gas age-ice age differences and the chronology of the Vostok ice core, 0-100 ka, J. Geophys. Res.-Atmos., 111, D21115, doi:10.1029/2005jd006488, 2006.
Buizert, C., Martinerie, P., Petrenko, V. V., Severinghaus, J. P., Trudinger, C. M., Witrant, E., Rosen, J. L., Orsi, A. J., Rubino, M., Etheridge, D. M., Steele, L. P., Hogan, C., Laube, J. C., Sturges, W. T., Levchenko, V. A., Smith, A. M., Levin, I., Conway, T. J., Dlugokencky, E. J., Lang, P. M., Kawamura, K., Jenk, T. M., White, J. W. C., Sowers, T., Schwander, J., and Blunier, T.: Gas transport in firn: multiple-tracer characterisation and model intercomparison for NEEM, Northern Greenland, Atmos. Chem. Phys., 12, 4259-4277, doi:10.5194/acp-12-4259-2012, 2012.

Caillon, N., Severinghaus, J. P., Jouzel, J., Barnola, J. M., Kang, J. C., and Lipenkov, V. Y.: Timing of atmospheric $\mathrm{CO}_{2}$ and Antarctic temperature changes across termination III, Science, 299, 1728-1731, doi:10.1126/Science.1078758, 2003.

Capron, E., Landais, A., Buiron, D., Cauquoin, A., Chappellaz, J., Debret, M., Jouzel, J., Leuenberger, M., Martinerie, P., MassonDelmotte, V., Mulvaney, R., Parrenin, F., and Prie, F.: Glacialinterglacial dynamics of Antarctic firn columns: Comparison between simulations and ice core air- $\delta^{15} \mathrm{~N}$ measurements, Clim. Past, 9, 983-999, doi:10.5194/cp-9-983-2013, 2013.

Clarke, G. K. C. and Waddington, E. D.: A 3-dimensional theory of wind pumping, J. Glaciol., 37, 89-96, 1991.

Colbeck, S. C.: Air movement in snow due to windpumping, J. Glaciol., 35, 209-213, 1989.

Courville, Z. R., Albert, M. R., Fahnestock, M. A., Cathles, L. M., and Shuman, C. A.: Impacts of an accumulation hiatus on the physical properties of firn at a low-accumulation polar site, J. Geophys. Res.-Earth, 112, F02030, doi:10.1029/2005jf000429, 2007.

Fahnestock, M. A., Scambos, T. A., Shuman, C. A., Arthern, R. J., Winebrenner, D. P., and Kwok, R.: Snow megadune fields on the East Antarctic Plateau: extreme atmosphere-ice interaction, Geophys. Res. Lett., 27, 3719-3722, doi:10.1029/1999g1011248, 2000.

Grachev, A. M. and Severinghaus, J. P.: Determining the thermal diffusion factor for ${ }^{40} \mathrm{Ar} /{ }^{36} \mathrm{Ar}$ in air to aid paleoreconstruction of abrupt climate change, J. Phys. Chem. A, 107, 4636-4642, doi:10.1021/Jp027817u, 2003a.

Grachev, A. M. and Severinghaus, J. P.: Laboratory determination of thermal diffusion constants for ${ }^{29} \mathrm{~N}_{2} /{ }^{28} \mathrm{~N}_{2}$ in air at temperatures from -60 to 0 degrees $\mathrm{C}$ for reconstruction of magnitudes of abrupt climate changes using the ice core fossilair paleothermometer, Geochim. Cosmochim. Ac., 67, 345-360, doi:10.1016/S0016-7037(02)01115-8, 2003b.

Grachev, A. M. and Severinghaus, J. P.: A revised $+10 \pm 4$ degrees $\mathrm{C}$ magnitude of the abrupt change in Greenland temperature at the Younger Dryas termination using published GISP2 gas isotope data and air thermal diffusion constants, Quaternary Sci Rev., 24, 513-519, doi:10.1016/J.Quascirev.2004.10.016, 2005.

Grew, K. E. and Ibbs, T. I.: Thermal Diffusion in Gases, Cambridge University Press, 1952.

Headly, M. A. and Severinghaus, J. P.: A method to measure $\mathrm{Kr} / \mathrm{N}_{2}$ ratios in air bubbles trapped in ice cores and its application in reconstructing past mean ocean temperature, J. Geophys. Res.Atmos., 112, D19105, doi:10.1029/2006jd008317, 2007.

Hörhold, M. W., Laepple, T., Freitag, J., Bigler, M., Fischer, H., and Kipfstuhl, S.: On the impact of impurities on the densification of polar firn, Earth Planet. Sci. Lett., 325, 93-99, doi:10.1016/J.Epsl.2011.12.022, 2012. 
Kawamura, K.: Variations of atmospheric components over the past 340000 years from Dome Fuji deep ice core, Antarctica, Ph.D. thesis, Tohoku University, Sendai, Japan, 2000.

Kawamura, K., Severinghaus, J. P., Ishidoya, S., Sugawara, S., Hashida, G., Motoyama, H., Fujii, Y., Aoki, S., and Nakazawa, T.: Convective mixing of air in firn at four polar sites, Earth Planet. Sci. Lett., 244, 672-682, doi:10.1016/J.Epsl.2006.02.017, 2006.

Keeling, R. F., Blaine, T., Paplawsky, B., Katz, L., Atwood, C., Brockwell, T.: Measurement of changes in atmospheric $\mathrm{Ar} / \mathrm{N}_{2}$ ratios using a rapid-switching, single-capillary mass spectrometer system, Tellus, 56B, 322-338, doi:10.1111/j.16000889.2004.00117.x, 2004.

Landais, A., Caillon, N., Goujon, C., Grachev, A. M., Barnola, J. M., Chappellaz, J., Jouzel, J., Masson-Delmotte, V., and Leuenberger, M.: Quantification of rapid temperature change during DO event 12 and phasing with methane inferred from air isotopic measurements, Earth Planet. Sci. Lett., 225, 221-232, doi:10.1016/j.eps1.2004.06.009, 2004.

Landais, A., Barnola, J. M., Kawamura, K., Caillon, N., Delmotte, M., Van Ommen, T., Dreyfus, G., Jouzel, J., Masson-Delmotte, V., Minster, B., Freitag, J., Leuenberger, M., Schwander, J., Huber, C., Etheridge, D., and Morgan, V.: Firn-air delta $\mathrm{N}^{15}$ in modern polar sites and glacial-interglacial ice: a model-data mismatch during glacial periods in Antarctica?, Quat. Sci. Rev., 25, 49-62, doi:10.1016/J.Quascirev.2005.06.007, 2006.

Lang, C., Leuenberger, M., Schwander, J., and Johnsen, S.: 16 degrees $\mathrm{C}$ rapid temperature variation in Central Greenland 70000 years ago, Science, 286, 934-937, doi:10.1126/Science.286.5441.934, 1999.

Parrenin, F., Barker, S., Blunier, T., Chappellaz, J., Jouzel, J., Landais, A., Masson-Delmotte, V., Schwander, J., and Veres, D.: On the gas-ice depth difference ( $\Delta$ depth) along the EPICA Dome C ice core, Clim. Past, 8, 1239-1255, doi:10.5194/cp-8-12392012, 2012.

Parrenin, F., Masson-Delmotte, V., Kohler, P., Raynaud, D., Paillard, D., Schwander, J., Barbante, C., Landais, A., Wegner, A., and Jouzel, J.: Synchronous change of atmospheric $\mathrm{CO}_{2}$ and Antarctic temperature during the last deglacial warming, Science, 339, 1060-1063, doi:10.1126/science.1226368, 2013.

Powers, D., Oneill, K., and Colbeck, S. C.: Theory of natural convection in snow, J. Geophys. Res.-Atmos., 90, 10641-10649, doi:10.1029/Jd090id06p10641, 1985.

Reid, R. C., Prausnitz, J. M., and Poling, B. E.: The Properties of Gases and Liquids, fourth edition, McGraw-Hill, New York, 753 pp., 1987.

Ritz, S. P., Stocker, T. F., and Severinghaus, J. P.: Noble gases as proxies of mean ocean temperature: sensitivity studies using a climate model of reduced complexity, Quat. Sci. Rev., 30, 37283741, doi:10.1016/J.Quascirev.2011.09.021, 2011.
Schwander, J.: The transformation of snow to ice and the occlusion of gases, in: The Environmental Record in Glaciers and Ice Sheets, edited by: Oeschger, H. and Langway, C. C., Wiley, New York, 53-67, 1989.

Schwander, J., Barnola, J. M., Andrie, C., Leuenberger, M., Ludin, A., Raynaud, D., and Stauffer, B.: The age of the air in the firn and the ice at Summit, Greenland, J. Geophys. Res.-Atmos., 98, 2831-2838, doi:10.1029/92jd02383, 1993.

Severinghaus, J. P. and Battle, M. O.: Fractionation of gases in polar ice during bubble close-off: New constraints from firn air $\mathrm{Ne}$, $\mathrm{Kr}$ and Xe observations, Earth Planet. Sci. Lett., 244, 474-500, doi:10.1016/J.Epsl.2006.01.032, 2006.

Severinghaus, J. P., Sowers, T., Brook, E. J., Alley, R. B., and Bender, M. L.: Timing of abrupt climate change at the end of the Younger Dryas interval from thermally fractionated gases in polar ice, Nature, 391, 141-146, doi:10.1038/34346, 1998.

Severinghaus, J. P., Grachev, A., and Battle, M.: Thermal fractionation of air in polar firn by seasonal temperature gradients, Geochem. Geophy. Geosy., 2, 1048, doi:10.1029/2000GC000146, 2001.

Severinghaus, J. P., Grachev, A., Luz, B., and Caillon, N.: A method for precise measurement of argon 40/36 and krypton/argon ratios in trapped air in polar ice with applications to past firn thickness and abrupt climate change in Greenland and at Siple Dome, Antarctica, Geochim. Cosmochim. Ac., 67, 325-343, doi:10.1016/S0016-7037(02)00965-1, 2003.

Severinghaus, J. P., Albert, M. R., Courville, Z. R., Fahnestock, M. A., Kawamura, K., Montzka, S. A., Muhle, J., Scambos, T. A., Shields, E., Shuman, C. A., Suwa, M., Tans, P., and Weiss, R. F.: Deep air convection in the firn at a zero-accumulation site, central Antarctica, Earth Planet. Sci. Lett., 293, 359-367, doi:10.1016/J.Eps1.2010.03.003, 2010.

Sowers, T., Bender, M., and Raynaud, D.: Elemental and isotopic composition of occluded $\mathrm{O}_{2}$ and $\mathrm{N}_{2}$ in polar ice, J. Geophys. Res.-Atmos., 94, 5137-5150, doi:10.1029/JD094id04p05137, 1989.

Sowers, T., Bender, M., Raynaud, D., and Korotkevich, Y. S.: $\delta \mathrm{N}^{15}$ of $\mathrm{N}_{2}$ in air trapped in polar ice - a tracer of gas transport in the firn and a possible constraint on ice age-gas age differences, J. Geophys. Res.-Atmos., 97, 15683-15697, 1992.

Trudinger, C. M., Enting, I. G., Etheridge, D. M., Francey, R. J., Levchenko, V. A., Steele, L. P., Raynaud, D., and Arnaud, L.: Modeling air movement and bubble trapping in firn, J. Geophys. Res.-Atmos., 102, 6747-6763, doi:10.1029/96jd03382, 1997.

Witrant, E., Martinerie, P., Hogan, C., Laube, J. C., Kawamura, K., Capron, E., Montzka, S. A., Dlugokencky, E. J., Etheridge, D., Blunier, T., and Sturges, W. T.: A new multi-gas constrained model of trace gas non-homogeneous transport in firn: evaluation and behaviour at eleven polar sites, Atmos. Chem. Phys., 12, 11465-11483, doi:10.5194/acp-12-11465-2012, 2012. 